\title{
The Irrelevance of a Moral Right to Privacy for Biomedical Moral Enhancement
}

\section{Ingmar Persson \& Julian Savulescu}

Jan Christoph Bublitz' critical discussion ${ }^{1}$ of our book Unfit for the Future ${ }^{2}$ provides us with a welcome opportunity to emphasize and expand on certain aspects of our views, in particular on whether there is a moral right to privacy. There are two points we wish to emphasize right at the outset. First, as Bublitz notes, we are denying the existence of moral right to privacy, not that there might be legal rights to privacy. Now, legal rights in an interesting sense aren't simply 'those that happen to be written in statutes and legal text books', as he suggests (2); they are rather such stated rights that are morally justifiable, though not necessarily by reference to moral rights, but perhaps by reference to the common good. We explicitly acknowledge that there may be such legal rights to privacy (Unfit, 5, 55). This will be illustrated below. The second point is that we take your (moral) right to privacy to be a right against others that they don't acquire (and sustain) certain (true) beliefs about you. This is compatible with the fact that 'the means they use to acquire beliefs about you, or the use to which they put these beliefs... could violate your rights' (Unfit, 53).

Turning to Bublitz' criticisms with these points in mind, we find that he hasn't properly taken them on board. As counter-examples to our denial of a moral right to privacy he cites systematically following someone around which 'many legal systems outlaw as stalking', and gawking at 'a woman who, because of some unfortunate event, lies naked and helpless on the street' (5). Now, in the latter case by gawking you would be acquiring information about a woman's body by taking advantage of or exploiting her being in circumstances in which she couldn't have been put by you without violating rights to her physical person. This would be so whether or not the woman has actually been put in these exposed circumstances by a wrongful act or by natural forces. It's morally wrong to take advantage of or exploit her being in such circumstances. To see this, it might help to consider another example: imagine that, through some unforeseeable mishap, a person transfers money from his own bank account to yours. Then you would be acting morally wrongly if you were to spend this money on getting a new car, and so on, though you don't violate any right of the person - it's your money now.

\footnotetext{
1 'Saving the World Through Sacrificing Liberties? A Critique of some Normative Arguments in Unfit for the Future', Neuroethics, this issue. Unprefixed page references in the text are to this article.
}

2 Oxford: Oxford U. P., 2012. 
Again, it would be wrong because you are taking advantage of or exploiting a situation you could only bring about by violating a right.

In the case of stalking, we could grant a legal right not to be systematically followed around, but we don't think that this right can be justified by a moral right to the same effect. The reason is this. We clearly don't have a moral right not be tailed and/or stared at for a short period of time. But it would be odd if such a right eventually kicks in if this period is gradually extended: how could the mere passage of time bring a moral right into existence? A more plausible explanation is that it's highly unlikely that someone takes the trouble of keeping an eye on somebody else for lengthy period of time, unless he plans to use this information for some purpose. It's most improbable that this purpose is one to which the victim would consent, for then why doesn't he ask her? Thus, it's likely that the stalker has designs on his victim that she would disapprove of. To nip such designs in their bud, a state could justifiably grant citizens a legal right not to be followed around in this fashion.

To clarify things further, consider again the moral right to property. If there is such a right, it would include a right to own weapons if they are acquired under conditions that would endow you with a right to other material things. There isn't anything wrong with simply owning weapons. However, there is a risk that owners of weapons will use them to violate the rights of others. This may morally justify the state to impose legal restrictions on the right to property which exclude or limit the ownership of weapons. Analogously, we may have a moral right to follow others around, but the state may legitimately impose restrictions on this right when the following around is so protracted that there is a risk that the information thereby gathered will be used to violate the rights of someone. Being followed around in this way makes us uneasy because we think that nobody would take the trouble to do so unless they are planning to take some action against us.

This story doesn't assume any moral right to privacy understood as a moral right against others that they don't acquire certain information about one's person. In fact, the acquisition of beliefs isn't even an action which could be carried out voluntarily, though it could occur by means of actions. For this reason alone, it would be odd to think we have a moral duty not to acquire certain beliefs: the objects of moral duty are plausibly things that are under the control of our will.

A thought-experiment (for many it's a reality) may make the implausibility of such a right clearer. Suppose there is a God, as conceived by Christians: an omniscient and morally perfect being. If there is a right to privacy, the conception of such a being would be inconsistent: by being omniscient this being would violate the right of privacy of countless 
human (and non-human?) beings and, thus, wouldn't be morally perfect. But the conception of such a being seems evidently consistent. The reason is that, being omnipotent, it wouldn't have to use any impermissible means to acquire its all-encompassing information, nor will it put it to any impermissible use, since it is morally perfect.

This creates a strong suspicion that Bublitz doesn't mean the same with 'privacy' as we do. Confirmation of this suspicion is supplied when he writes that by a right to privacy he means 'a right against the unlicensed collection and use of private information' (7, our emphasis). But, to repeat, we take it cover only the collection or acquisition of private information. Furthermore, there is evidence that he takes a denial of a right to privacy to imply a permission to use (bodily) invasive means to collect private information. As he notes (7), in Unfit (21-5) we give reasons for being skeptical of moral or natural rights in general, but we argue that the case for a right to privacy is weaker than the case for some other rights, like the right to property. Bublitz suggests that this position is inconsistent: 'whoever acknowledges property rights should likewise accept rights to the person, of which mental privacy is an indispensible (sic) part' (10, n. 2). Referring to John Locke, however, we do assume that property rights presuppose a right to our person, body and mind. But why does he think that a right to 'mental privacy is an indispensable part' of a right to our person? Presumably because he tacitly takes it for granted that information about our states of mind must be collected through invasive means which infringe the right to our bodies. Now, we argue that means are only invasive in a clear sense if they invade our bodies - and thus may violate rights assumed for the sake of the argument - but try to show with various thought experiments about super-senses etcetera that such invasion isn't strictly necessary for the acquisition of private information (see also the example of God above).

Even more importantly, his different use of 'privacy' also surfaces in his asking the question: 'Is there a right (to privacy) against moral bioenhancements?' (7). According to our understanding of privacy, the answer to this question is obviously 'no', since it covers only the acquisition of information about our states of mind (for example), and not changing them as moral (bio)enhancements clearly do. Likewise, we would draw a clear distinction between privacy and integrity, according to which not respecting the integrity of people would necessitate interference with them, but Bublitz apparently doesn't (8). All this goes to show that we should put aside the issue of a right to privacy as irrelevant to the issue of the permissibility of moral bioenhancement.

As regards this permissibility, the first thing to notice is that its implications aren't as strong as he believes. He writes: ‘the permission to intervene into another person's mind... 
implies, conversely, a duty of the person to be in the mental state to be induced through the intervention' (11). This is a mistake: for example, Bublitz may be permitted to win a race in which we are also competing. Plainly, this doesn't imply that we are under a duty to let him win; we are also permitted to win.

Another mistake of his, which he has in common with a number of other critics of us, comes out in this passage: 'Traditional means of moral education or public awareness campaigns... engage with the other person as a rational being by appealing to argument, opinions and to visions of a good and just society', whereas 'moral bioenhancements... 'bypass rational and imaginative capacities' (9). But when we teach small children a language or basic arithmetic, we obviously don't do it 'by appealing to argument, opinions and to visions of a good and just society'; these children aren't sufficiently mentally developed for this to be feasible. It's just a plain matter of fact that a lot of the training needed to turn illiterate beings like infants into members of our civilization must occur without their consent and appeals to their rationality.

Secondly, as we show at some length in our response to Schlag, some of the moral bioenhancements we have in mind can be voluntary and, thus, as Bublitz concedes 'considerably less problematic'. For instance: 'Supporting persons in living up to resolutions they set for themselves' (9).

He also charges us with a methodological individualism which denies his claim that 'there might be higher level processes that are independent of individual minds, or have become so through historical developments, i.e. they might persist even when individual minds are altered' (13). Certainly, he is right in maintaining that morally bioenhancing a few individuals, even if they be highly influential, like a CEO in a big company, or a leading politician won't likely be enough to reform radically a society. But if we enhance the functioning of not just a few cogs, but most of the cogs of the machinery, won't this enhance its functioning? In other words, we don't believe in the existence of 'higher level' social processes or structures that are independent of the minds of a large majority of the citizens, such that they would persist even if these minds are altered.

Bublitz also claims that 'the main factor that drives the exploitation of natural resources is the production of goods' or 'incessant economic growth' (14). We agree, but we ask what drives the latter. Ultimately, we believe that this must be human psychology, their motivation and reason. Suppose that most human beings, throughout their history, had had a psychology and ideals like, say, Diogenes the Cynic (who is said to have lived in a barrel); then humanity today surely wouldn't be at the brink of depleting the natural resources of the planet. 
Finally, we don't 'champion property rights' (14); as Bublitz elsewhere remarks, we are skeptical of rights. He wrongly accuses us of wanting to halt climate change and achieve sustainability by sacrificing the privacy and integrity of citizens rather than by interfering with the capitalist market economy. This is a complete misunderstanding. If the moral (bio)enhancement we think is necessary to establish global sustainability would also bring about the downfall of capitalism, then so be it. While the subversion of capitalism isn't a primary end of ours, it may well be a means or side-effect of establishing global sustainability. 